\title{
Thermal Behavior of Externally Driven Spindle: Experimental Study and Modelling
}

\author{
Christian Brecher'1, Yair Shneor², Stephan Neus', Kolja Bakarinow ${ }^{1}$, Marcel Fey ${ }^{1}$ \\ ${ }^{1}$ RWTH Aachen University, Laboratory for Machine Tools and Production Engineering, Chair of Machine Tools, \\ Aachen, Germany \\ ${ }^{2}$ CAMT, Center for Advanced Manufacturing Technologies, Rotem Industries, Rotem Industrial Park, Mishor \\ Yamin, D.N. Arava, Israel \\ Email: camt@rotemi.co.il, s.neus@wzl.rwth-aachen.de
}

Received 6 February 2015; accepted 24 February 2015; published 27 February 2015

Copyright @ 2015 by authors and Scientific Research Publishing Inc.

This work is licensed under the Creative Commons Attribution International License (CC BY).

http://creativecommons.org/licenses/by/4.0/

(c) (i) Open Access

\section{Abstract}

This paper focuses on model development for computer analysis of the thermal behavior of an externally driven spindle. The aim of the developed model is to enable efficient quantitative estimation of the thermal characteristics of the main spindle unit in an early stage of the development process. The presented work includes an experimental validation of the simulation model using a custom-built test rig. Specifically, the effects of the heat generated in the bearings and the heat flux from the bearing to the adjacent spindle system elements are investigated. Simulation and experimental results are compared and demonstrate good accordance. The proposed model is a useful, efficient and validated tool for quantitative simulation of thermal behavior of a main spindle system.

\section{Keywords}

Machine Tool, Thermal Behavior, Heat Transfer, Spindle Modelling

\section{Introduction}

The accuracy of a machine tool is influenced by its static, dynamic and thermo-elastic behavior [1]. The influence of a machine tool's thermal behavior on the machining process accuracy and repeatability has been the focus of research since the 1960s [2]. Main spindle systems contribute significantly to the final workpiece accuracy. The thermal properties of the main spindle unit as well as its rotational accuracy and static and dynamic stiffness affect the accuracy of the manufactured part. Advances in mechatronics have led to a higher precision of machine tools. However, the predictability of the thermal stability of machine tools becomes more critical, 
especially to avoid costly design modifications in latter stages of machine development based on experimental studies [3]. Due to the significance of the main spindle's thermal behavior on machine tool manufacturing accuracy, a good understanding of the thermal interaction among different spindle components in practical spindle systems is required [4].

The spindle system's overall behavior strongly depends on the design and structure of the employed components. Particularly, the behavior of high-speed spindles can vary significantly according to the direction or arrangement of its components. For example, the arrangement of bearing sets, motor placement and motor coolant jackets in the housing, fits between bearings, housing design and bearing preload mainly influence the spindle behavior during high speed operation.

Spindle bearing friction is the main reason for bearing heat generation, which limits the maximum achievable spindle speed. As speed increases, there is an increase in generated heat in the bearings, the motor and the cutting surface. This additional heat causes thermal expansion. The amount of heat generated in the bearing should be estimated within the design process in order to choose the proper types of bearings and drives.

Angular contact ball bearings are most widely used for high speed spindles due to their properties under high speed conditions [5]. The bearings outer ring temperature is commonly used to detect early bearing failure, since expansion causes increased bearing loads and can lead to seizure [6].

Therefore, it is important to include the spindle's and bearing's thermal effects on the prediction of the overall response at elevated rotational speeds. The thermal models of bearing and spindle must be combined to provide a comprehensive representation of the heat transfer mechanisms.

Many attempts have been made to model the thermal behavior of the spindle and bearings for more than 60 years [7]. The Finite Element Method (FEM) is widely used to formulate the thermo-mechanical model of the bearing and spindle system [8]-[10]. The FEM models include the dynamic stiffness of the bearings, contact forces, temperature distributions and thermal expansions. The main drawback of this method is that it cannot be applied and adapted to different types of systems and conditions of operation in an efficient and fast manner. Besides, the standard software does not incorporate the models for numerical estimation of heat generation in the bearings and requires a lot of preparatory work [10].

In order to achieve a better understanding of the thermal behavior of the main spindle and its influence on the surroundings, it is not sufficient to use specially designed test rigs for the testing of individual spindle components. Beyond that, an examination of the entire spindle system is required. For this reason a custom-designed modular test rig was built. Different machine tool spindles can be operated on this test rig under a variety of testing conditions. During the early stages of design and as a part of the comprehensive effort to define the error caused by thermal expansion due to spindle operation, a thermal model of the spindle system was developed, following the purpose of increasing the efficiency of evaluating the thermal behavior of such spindle systems. Using the model and software developed, a fast numerical evaluation of the effect of machining operation parameters on the heat transfer mechanism within the main spindle system was obtained.

For the purpose of model validation, an experimental study was conducted using a custom-built test rig. In this paper the test rig configuration and experimental work for the externally driven spindle's thermal behavior are investigated. In this spindle as a special case study, the only heat generation sources are the bearings. The experimental work is followed by modelling and simulation of the thermal behavior of the spindle system using Wolfram Mathematica ${ }^{\circledR}$ software.

\section{Simulation Model Development}

The purpose of the spindle bearing model is the calculation of heat generation, heat transfer and temperature distribution over the spindle and housing elements. The developed model is coupled with the thermal models of the bearing to obtain a thermal response of the whole spindle system. The following assumptions were made [6]:

- Shaft and housing are assumed to be radially axisymmetric about the centerline of the spindle.

- The primary analysis will be one-dimensional in the axial direction. Radial heat loss in the housing will also be considered.

- Any heat generation (or cooling) is assumed to occur at the bearing contact zone, the center of the spindle (as in a centrally located motor), or the tips of the spindle (cutting heat and motor heat).

Although there are many simplifications, this heat transfer model can be used to examine the temperature fields in the bearings, housing and spindle shaft by examining the actual spindle bearing assembly. Without loss 
of generality, the proposed heat transfer model is developed based on an externally driven grinding spindle with maximum spindle speed of $7000 \mathrm{rpm}$ and a bearing bore diameter of $85 \mathrm{~mm}$.

\subsection{Bearing Heat Generation}

The externally driven grinding spindle investigated in this research is assembled with sealed universal bearings with small steel balls. Figure 1 illustrates the basic method used for defining heat transfer through the spindle and housing.

The heat is mainly generated in the contact between bearing raceways and balls due to frictional losses and rolling friction, influenced by speed, preload and lubricant. The cutting process is also a heat source. All three types of heat are the result of rotating motion and they are calculated from torque and speeds. The equation combining all three sources of heat is [8]:

$$
q_{\text {brg }}=q_{\text {brg_l }}+q_{\text {brg_v } v}+q_{\text {brg_s }}
$$

where $q_{\mathrm{brg}}$ is the heat flux from the bearing, $l, v$ and $s$ stand for load, viscosity and rotational speed, respectively. All three types of heat are generated at the contact between the ball surfaces and bearing raceways. Prior to the solution of thermal steady-state behavior, bearing heat generation must be calculated. According to Palmgren [7] and Harris [11], the total friction torque in the bearings is related to load, viscosity and rotational speed. By replacing the bearing loading forces with bearing contact loads expressions, the equations for inner and outer rolling resistance torque, $M_{i(\text { inner ring) }}, M_{e \text { (outer ring) }}$, related to load and viscosity at each ball can be expressed as [6]:

$$
\begin{aligned}
& M_{f i}=M_{i(\text { inner ring })}=\left[0.675 f_{0}\right]\left(\eta \omega_{\text {roll }}\right)^{2 / 3} D^{3}+f_{1}\left(\frac{Q_{i}}{Q_{i \_ \text {max }}}\right)^{1 / 3} Q_{i} D ; \\
& M_{f o}=M_{e(\text { outer ring })}=\left[0.675 f_{0}\right]\left(\eta \omega_{\text {roll }}\right)^{2 / 3} D^{3}+f_{1}\left(\frac{Q_{e}}{Q_{e \_ \text {max }}}\right)^{1 / 3} Q_{e} D .
\end{aligned}
$$

The bearing parameters $f_{0}$ and $f_{1}$ are dependent on the bearing and lubrication type. For angular contact ball bearings, $f_{0}$ is equal to 2.0 for grease and $f_{1}$ is equal to 0.001 for oil-air. The kinematic viscosity $\eta$ $\left(\mathrm{m}^{2} / \mathrm{s}\right)$ is found using the operating lubricant temperature. The ball's rolling velocity is

$$
\omega_{\text {roll }}=\omega d_{m} / D
$$

where $D$ is the ball diameter $(\mathrm{m}), \omega$ is the inner ring velocity (rad/s). $Q_{i}, Q_{e}$ and $Q_{i \_ \text {max }}, Q_{e_{\text {_max }}}(\mathrm{N})$, are the ball contact load and ball maximum contact load at the contact point of the inner ring and the ball and the outer ring and the ball, respectively. The rotational speed related rolling resistance torque, $M_{\text {si(inner ring) }}$, $M_{\text {se(outer ring) }}$ can be expressed as:

$$
\begin{aligned}
& M_{\text {si(inner) }}=\frac{3 k_{s} Q_{i} a_{i} \lambda}{8} ; \\
& M_{\text {se(outer })}=\frac{3 k_{s} Q_{e} a_{e} \lambda}{8}
\end{aligned}
$$

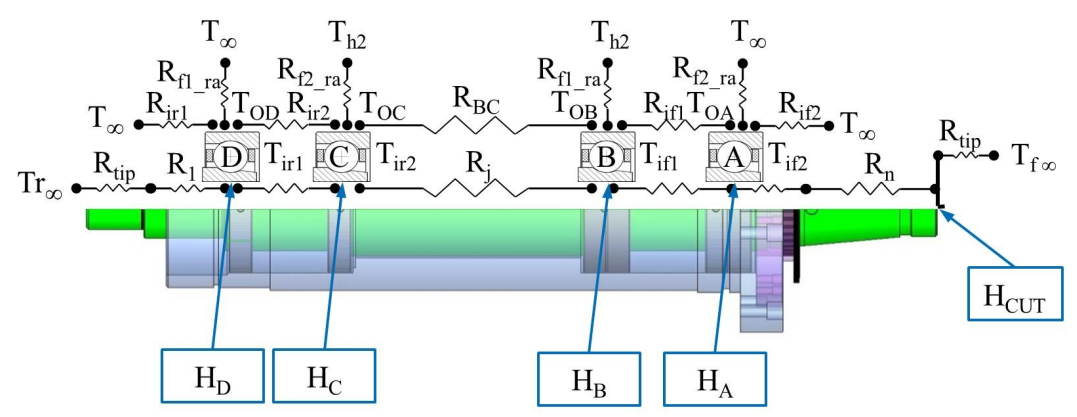

Figure 1. The investigated spindle and housing geometry definition including heat sources. 
where $k_{s}$ is the friction coefficient, $a_{e}, a_{i}$ are the major axes of the inner and outer contact ellipse area and $\lambda$ is the contact area geometry factor [6]. The heat generation in the inner ring $H_{i k}$ and outer ring $H_{e k}$ contact zone for ball $k$, is found from the power loss equation, where power is rotational speed times moment.

$$
\begin{aligned}
& H_{i k}=\omega_{\text {roll }} M_{f i}+\omega_{s i} M_{s i} ; \\
& H_{e k}=\omega_{\text {roll }} M_{f o}+\omega_{s e} M_{s e} .
\end{aligned}
$$

It is assumed that for grease lubrication all heat generation enters the combined ball/ring network. The overall bearing heat generation is the summation of the contact heat generation at the inner and outer rings [8]. The housing will experience the heat generated from the outer ring $H_{e}$, while the spindle shaft receives heat generation from the inner ring $H_{i}$.

$$
H_{i}=\sum_{k=1}^{N_{b}} H_{i k}, \quad H_{e}=\sum_{k=1}^{N_{b}} H_{e k}
$$

where $N_{b}$ is the total number of balls in the bearing. The Hertzian contact theory is used in this study to compute the contact loads $Q_{i}, Q_{e}$ between bearing balls and bearing rings. The Hertzian inner and outer contact loads for each ball are shown in Figure 2 and expressed by [12]-[14]:

$$
\begin{aligned}
& Q_{i k}=K_{i} \delta_{i k}^{3 / 2} ; \\
& Q_{e k}=K_{o} \delta_{o k}^{3 / 2}
\end{aligned}
$$

where $k$ is the ball index, $\delta_{i k}, \delta_{o k}$ are the relative normal contact displacement between ball, inner and outer ring. $K_{i}$ and $K_{o}$, the load deflection parameters can be obtained using the equations shown in Appendix A [11] [14].

The bearing displacement vector $\{\delta\}$ describes the three linear and two rotational motions, $\left[\delta_{x} \delta_{y} \delta_{z} \gamma_{y} \gamma_{z}\right]^{\mathrm{T}}$. Due to the external forces applied to the bearings, displacements appear within the inner and outer rings and the distance between the curvature centers of the bearing rings change, as shown in Figure 3 [14]. The relative displacement between the inner ring and the outer ring can be expressed as:

$$
\Delta \delta_{x}=\delta_{x}^{i}-\delta_{x}^{0} ; \Delta \delta_{y}=\delta_{y}^{i}-\delta_{y}^{o} ; \Delta \delta_{z}=\delta_{z}^{i}-\delta_{z}^{o} ; \Delta \gamma_{y}=\gamma_{y}^{i}-\gamma_{y}^{o} ; \Delta \gamma_{z}=\gamma_{z}^{i}-\gamma_{z}^{o}
$$

where $B_{d}$ is the distance between the curvature centers of the inner and outer rings before deformation of the bearing and can be represented as:

$$
\begin{gathered}
B_{d}=B D=\left(f_{o}+f_{i}-1\right) D . \\
f_{i}=\frac{r_{\text {in }}}{D} ; \quad f_{o}=\frac{r_{\text {ou }}}{D}
\end{gathered}
$$

As shown in Figure 3, where $k$ is the ball index. $\Delta_{i k}$ and $\Delta_{o k}$ can be expressed as:

$$
\begin{aligned}
& \Delta_{i k}=r_{i n}-D / 2+\delta_{i k}=\left(f_{i n}-0.5\right) D+\delta_{i k} ; \\
& \Delta_{o k}=r_{o u}-D / 2+\delta_{o k}=\left(f_{o}-0.5\right) D+\delta_{o k} .
\end{aligned}
$$

The following relations are derived from Figure 3:

$$
\begin{aligned}
& \sin \theta_{o k}=\frac{U_{k}}{\left(r_{o} / D-0.5 D\right)+\delta_{o k}} ; \\
& \cos \theta_{o k}=\frac{V_{k}}{\left(r_{o} / D-0.5 D\right)+\delta_{o k}} ; \\
& \sin \theta_{i k}=\frac{U_{i k}-U_{k}}{\left(r_{i} / D-0.5 D\right)+\delta_{i k}} ; \\
& \cos \theta_{i k}=\frac{V_{i k}-V_{k}}{\left(r_{i} / D-0.5 D\right)+\delta_{i k}} ;
\end{aligned}
$$

The equilibrium equations for the bearing ball as shown in Figure 2(c) can be expressed as [14]: 


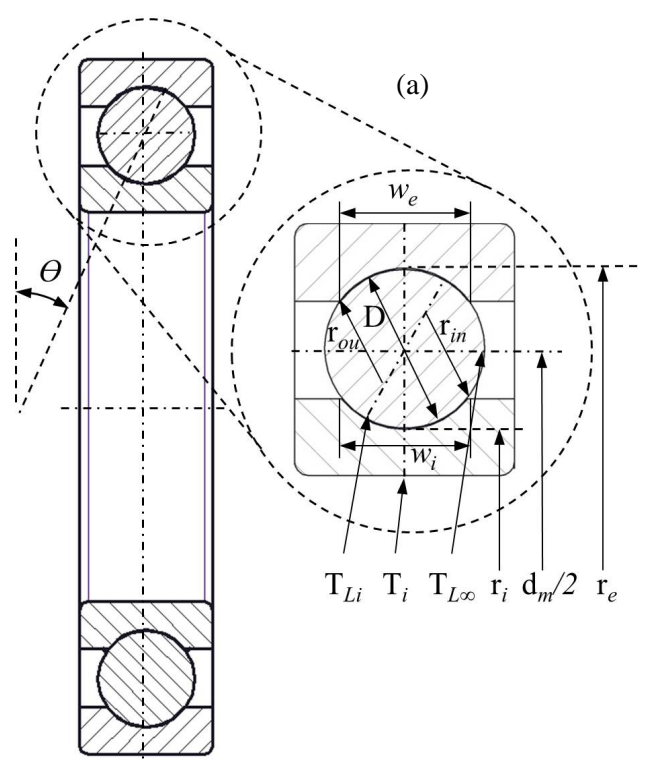

(b)

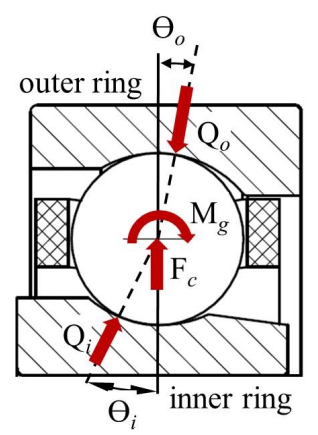

Figure 2. Angular contact ball bearings. (a) Geometry and temperature terms; (b) Loads diagram [15]; (c) Forces acting on the bearing ball [14].

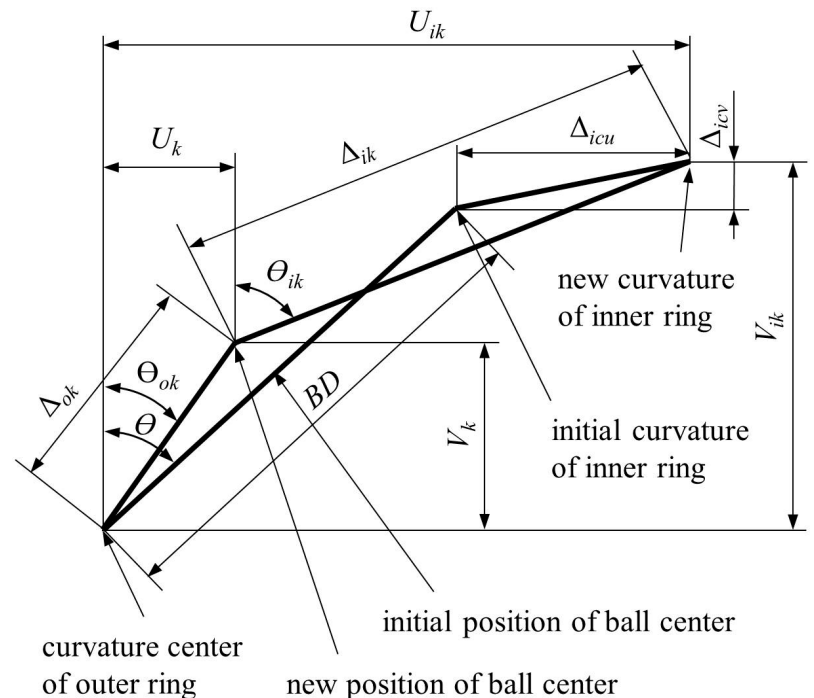

Figure 3. Displacement relationships between curvature centers of bearing rings under load [14].

$$
\begin{aligned}
& Q_{o k} \cos \theta_{o k}-\frac{M_{g k}}{D} \sin \theta_{o k}-Q_{i k} \cos \theta_{i k}+\frac{M_{g k}}{D} \sin \theta_{i k}-F_{c k}=0 ; \\
& Q_{o k} \sin \theta_{o k}+\frac{M_{g k}}{D} \cos \theta_{o k}-Q_{i k} \sin \theta_{i k}-\frac{M_{g k}}{D} \cos \theta_{i k}=0
\end{aligned}
$$

where $F_{c k}$ and $M_{g k}$ are the centrifugal force and gyroscopic moment, respectively [14]. The displacement equations for the bearing ball as shown in Figure 3 can be expressed as [14]:

$$
\begin{aligned}
& \left(U_{i k}-U_{k}\right)^{2}+\left(V_{i k}-V_{k}\right)^{2}-\Delta_{i k}^{2}=0 ; \\
& \left(U_{k}\right)^{2}+\left(V_{k}\right)^{2}-\Delta_{o k}^{2}=0 .
\end{aligned}
$$


For $\varphi_{k}=2 \pi k / N, N$ is the total number of balls in the bearing, $\theta$ is the initial contact angle, $U_{i k}, V_{i k}$ in Equation (14) will be:

$$
\begin{gathered}
U_{i k}=B D \sin \theta+\Delta \delta_{x}-\Delta \gamma_{z} r_{i c} \cos \varphi_{k}+\Delta \gamma_{y} r_{i c} \sin \varphi_{k} ; \\
V_{i k}=B D \cos \theta+\Delta \delta_{y} \cos \varphi_{k}+\Delta \delta_{z} \sin \varphi_{k} . \\
r_{i c}=\frac{D_{m}}{2}+\left(f_{i}-0.5\right) D \cos \theta
\end{gathered}
$$

$r_{\text {ic }}$ in Equation (16) is the radius from the bearing center to the inner ring curvature center shown in Figure 2(a). The four unknown parameters, $\left\{\boldsymbol{\delta}_{k}\right\}=\left\{U_{k}, V_{k}, \delta_{o k}, \delta_{i k}\right\}^{\mathrm{T}}$ must be obtained by solving Equations (13), (14) iteratively using the approach [14]:

$$
\left\{\delta_{k}^{(n+1)}\right\}=\left\{\delta_{k}^{(n)}\right\}-\left[a_{i j}^{(n)}\right]^{-1}\left\{\varepsilon_{k}^{(n)}\right\} ; \quad(n=0,1,2, \cdots ; i, j=1,2,3,4)
$$

$\left\{\varepsilon_{k}\right\}=\left\{\varepsilon_{1}, \varepsilon_{2}, \varepsilon_{3}, \varepsilon_{4}\right\}^{\mathrm{T}}$ is the error vector and should converge to a specifically defined small value. The coefficients matrix $\left[\boldsymbol{a}_{i j}\right]$ can be expressed as:

$$
\left[\boldsymbol{a}_{i j}\right]=\left[\frac{\partial\left\{\boldsymbol{\varepsilon}_{k}\right\}_{i}}{\partial\left\{\boldsymbol{\delta}_{k}\right\}_{i j}}\right] ; \quad(i, j=1,2,3,4) .
$$

The elements of the error vector $\left\{\boldsymbol{\varepsilon}_{k}\right\}$ are:

$$
\begin{aligned}
& \left(U_{i k}-U_{k}\right)^{2}+\left(V_{i k}-V_{k}\right)^{2}-\Delta_{i k}^{2}=\varepsilon_{1} ; \\
& \left(U_{k}\right)^{2}+\left(V_{k}\right)^{2}-\Delta_{o k}^{2}=\varepsilon_{2} ; \\
& Q_{o k} \cos \theta_{o k}-\frac{M_{g k}}{D} \sin \theta_{o k}-Q_{i k} \cos \theta_{i k}+\frac{M_{g k}}{D} \sin \theta_{i k}-F_{c k}=\varepsilon_{3} ; \\
& Q_{o k} \sin \theta_{o k}+\frac{M_{g k}}{D} \cos \theta_{o k}-Q_{i k} \sin \theta_{i k}-\frac{M_{g k}}{D} \cos \theta_{i k}=\varepsilon_{4} .
\end{aligned}
$$

The bearing's contact loads $Q_{i k}, Q_{o k}$ in Equation (7) are obtained using the calculated values of $\left\{\boldsymbol{\delta}_{k}\right\}$. The bearing heat generation can be computed by Equations (2)-(6) using the calculated variables values. Knowing the bearing heat generation quantity, we can move forward to the thermal model of spindle and housing.

\subsection{Spindle and Housing Thermal Model}

The developed model is based on representing the spindle and the housing using axisymmetric thermal resistance elements. For the solution, the input parameters are: geometry, material parameters, air temperature, heat generation due to the bearings and initial temperature of the system. The thermal resistance is calculated for each housing and spindle element. Linear thermal resistance is defined according to the following equation [6]:

$$
R=\frac{L}{K A}
$$

where $L$ is the element length, $K$ is the material thermal conductivity and $A$ is the cross-sectional area.

\subsubsection{Bearing Heat Transfer Model}

Figure 4 shows the bearing geometry and temperature nodes definition as well as the bearing heat transfer model. The externally driven spindle is grease lubricated. With grease-packed lubrication, heat convection is less significant and conduction is more prominent. The radial heat transfer through the spindle, rolling element and housing is described similar to the thermal resistance network described by Jorgensen [6] and is shown in Figure 4. 


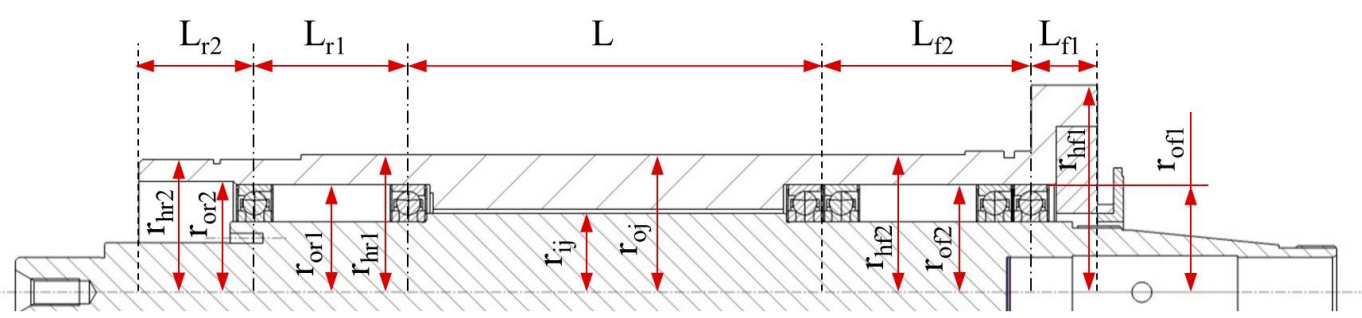

Figure 4. Bearing heat resistances model.

$$
\begin{aligned}
& R_{L i}=\frac{r_{b}}{k_{l}\left(\frac{2 \pi}{n} r_{i} W_{i}-\pi r_{b}^{2}\right)} ; \quad R_{L e}=\frac{r_{b}}{k_{l}\left(\frac{2 \pi}{n} r_{e} W_{e}-\pi r_{b}^{2}\right)} ; \quad R_{b}=\frac{1}{k_{b} \pi r_{b}} ; \quad R_{1}=\frac{1}{\frac{1}{R_{L e}}+\frac{1}{R_{b} / 2}}=\frac{R_{L e}\left(R_{b} / 2\right)}{R_{L e}+R_{b} / 2} ; \\
& R_{2}=\frac{1}{\frac{1}{R_{L i}}+\frac{1}{R_{b} / 2}}=\frac{R_{L i}\left(R_{b} / 2\right)}{R_{L i}+R_{b} / 2} ; \quad R_{e}=\frac{1}{k_{e}} \frac{n \ln \left(r_{o} / r_{e}\right)}{2 \pi W} ; \quad R_{i}=\frac{1}{k_{i}} \frac{n \ln \left(r_{i} / r_{s}\right)}{2 \pi W} .
\end{aligned}
$$

The heat transfer equations use temperatures at the edge of the inner and outer rings as boundary conditions. As an alternative solution method, the outer ring temperature can be easily measured and applied to the solution, allowing the housing approximations to be ignored. Steady state outer ring temperatures can be used to provide a reference point for the thermal equations [6]. The matrix form of the heat transfer equations can be expressed as:

$$
\left[\boldsymbol{R}_{b}\right]\{\boldsymbol{T}\}=\{\boldsymbol{H}\}
$$

where $\left[\boldsymbol{R}_{\boldsymbol{b}}\right]$ is the system heat resistance matrix; $\{\boldsymbol{T}\}$ is the vector of unknown temperatures, in this case three unknowns, and $\{\boldsymbol{H}\}$ are the heat generation inputs. As shown in Figure 4, Equation (22) can be written as:

$$
\left[\begin{array}{ccc}
R_{b 11} & R_{b 12} & 0 \\
R_{b 21} & R_{b 22} & R_{b 23} \\
0 & R_{b 32} & R_{b 33}
\end{array}\right]\left\{\begin{array}{c}
T_{L e} \\
T_{b} \\
T_{L i}
\end{array}\right\}=\left\{\begin{array}{c}
H_{L e} \\
H_{b} \\
H_{L i}
\end{array}\right\}=\left\{\begin{array}{c}
H_{e}+T_{O} / R_{e} \\
0.0 \\
H_{i}+T_{i} / R_{i}
\end{array}\right\}
$$

The resistance matrix elements, $R_{b i j}$ as well as the expressions for the generated heat can be found in Appendix B. Solving Equation (22) allows to predict the contact points' temperatures $T_{L e}, T_{L i}$ as well as the bearing ball temperature $T_{b}$. Although the heat transfer equations are approximations, sufficient accuracy is attainable for thermal expansion predictions [6].

\subsubsection{Housing Heat Transfer Model}

The housing heat transfer model based on quasi-two-dimensional analysis of heat flow is shown in Figure 1. The geometry parameters are shown in Figure 5. The four unknown nodal points' temperatures, $T_{o A}, T_{o B}, T_{o C}$, $T_{o D}$, shown in Figure 1, were calculated by applying axial and radial conduction and convection resistance elements. The radial and axial resistances for an element can be expressed as:

$$
\begin{gathered}
R_{\mathrm{rad}}=\frac{\ln \left(\frac{r_{h}}{r_{o}}\right)}{k_{h} 2 \pi L}+\frac{1}{h_{\mathrm{air}} L 2 \pi r_{h}} ; \\
R_{a x}=\frac{L}{k_{h} \pi\left(r_{h}^{2}-r_{o}^{2}\right)}+\frac{1}{h_{a i r} \pi\left(r_{h}^{2}-r_{o}^{2}\right)}
\end{gathered}
$$

where $r_{h}$ and $r_{o}$ are the outer (housing) and inner (housing) element radius. $L$ is the element length, $k_{h}$ is the housing element thermal conductivity and $k_{\text {air }}$ is the heat convection coefficient in air. The first part in Equations (24) and (25) is the radial and axial conduction resistance, respectively. The second part in Equations (24) and (25) is the radial and axial convection resistance. The second parts will be equal to zero if there are no free 


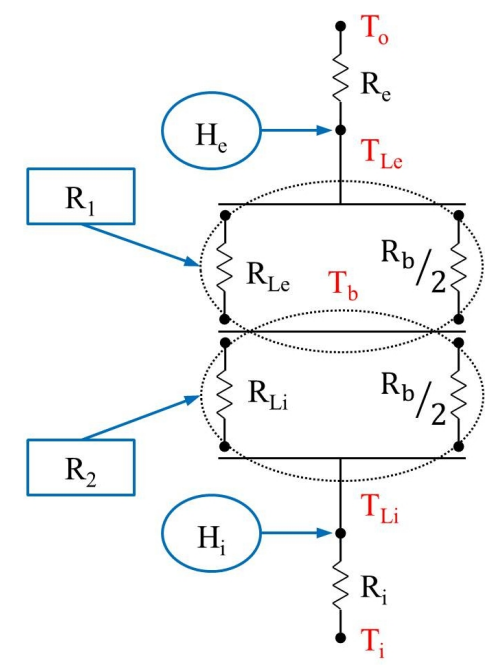

Figure 5. Spindle and housing 2D configuration.

ends in the element. In order to simplify the heat transfer equilibrium equation the axial and radial element resistance are combined as shown in the following equation:

$$
R_{\text {total }}=\frac{R_{a x} \times R_{\text {rad }}}{R_{\text {rad }}+R_{a x}}
$$

$R_{\text {total }}$ is the element total resistance. The housing heat transfer equations in matrix can be expressed as:

$$
\left[\boldsymbol{R}_{\boldsymbol{h}}\right]\{\boldsymbol{T}\}=\{\boldsymbol{H}\}
$$

where $R_{A}$ and $R_{D}$ are the total resistance of the front and rear housing elements. $R_{B C_{\_} \text {rad }}$ is the resistance of the connection element between points $B$ and $C$. The resistance matrix elements $R_{h i j}$ as well as the expressions for generated heat and the resistances $R_{A}, R_{D}$ and $R_{\mathrm{BC} C_{-} \text {rad }}$ can be found in Appendix C. By solving the set of Equation (27), the temperature values at the four most heated points along the housing outside surface are obtained.

$$
\left[\begin{array}{cccc}
R_{h 11} & R_{h 12} & 0 & 0 \\
R_{h 21} & R_{h 22} & R_{h 23} & 0 \\
0 & R_{h 32} & R_{h 33} & R_{h 34} \\
0 & 0 & R_{h 43} & R_{h 44}
\end{array}\right]\left\{\begin{array}{c}
T_{O A} \\
T_{O B} \\
T_{O C} \\
T_{O D}
\end{array}\right\}=\left\{\begin{array}{c}
H_{O A}+\frac{T_{\infty}}{R_{A}} \\
H_{O B}+\frac{T_{h 2}}{R_{B C \_r a d}} \\
H_{O C}+\frac{T_{h 2}}{R_{B C \_ \text {rad }}} \\
H_{O D}+\frac{T_{\infty}}{R_{D}}
\end{array}\right\}
$$

\subsubsection{Spindle Shaft Heat Transfer Model}

As shown in Figure 6, the spindle shaft is represented by a nine resistance element model. By applying the same matrix notation as above, the matrix notation of the heat generation balance is obtained:

$$
\left[\boldsymbol{R}_{\boldsymbol{i}}\right]\{\boldsymbol{T}\}=\{\boldsymbol{H}\}
$$

where $\left[\boldsymbol{R}_{\boldsymbol{i}}\right]$ is the spindle shaft heat resistance matrix, $\{\boldsymbol{T}\}$ is the vector of unknown temperatures in points of interest along the shaft axis, in this case six unknowns, and $\{\boldsymbol{H}\}$ is the heat generation inputs. The spindle shaft heat transfer set of equations can be expressed as: 


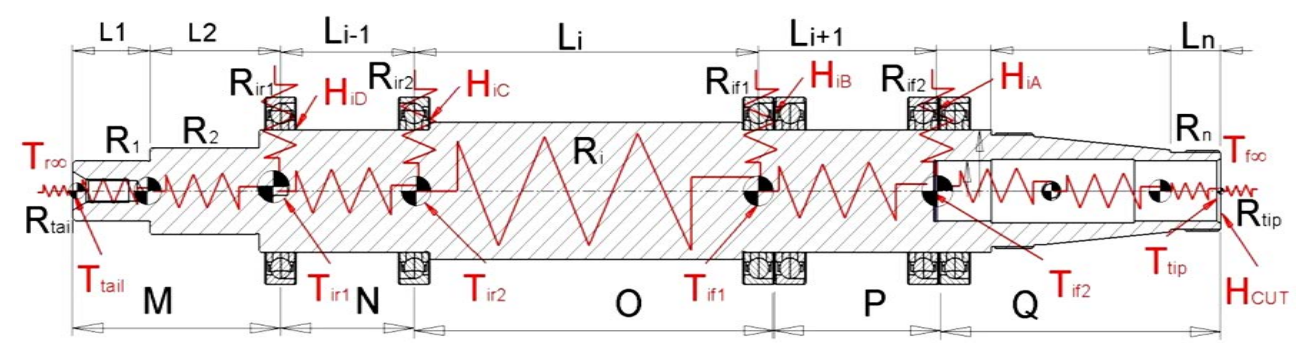

Figure 6. Spindle shaft heat transfer net.

$$
\left[\begin{array}{cccccc}
R_{i 11} & R_{i 12} & & & & \\
R_{i 21} & R_{i 22} & R_{i 23} & & 0 & \\
0 & R_{i 32} & R_{i 33} & R_{i 34} & & \\
& & R_{i 43} & R_{i 44} & R_{i 45} & \\
& 0 & & R_{i 54} & R_{i 55} & R_{i 56} \\
& & & & R_{i 65} & R_{i 66}
\end{array}\right]\left\{\begin{array}{c}
T_{\text {tail }} \\
T_{i r 1} \\
T_{i r 2} \\
T_{i f 1} \\
T_{i f 2} \\
T_{\text {tip }}
\end{array}\right\}=\left\{\begin{array}{c}
T_{r \infty} / R_{\text {tail }} \\
H_{i D} \\
H_{i C} \\
H_{i B} \\
H_{i A} \\
T_{f \infty} / R_{\text {tip }}
\end{array}\right\}
$$

All matrix and vector elements presented in Equation (30) are expressed in Appendix D. By solving the set of Equation (30), the temperature values in six points of interest along the spindle shaft centre are obtained.

\section{Experimental Setup for Spindle System Analysis}

The configuration of the test rig used for experimental investigations of an externally driven spindle is shown in Figure 7 and Figure 8. An air-cooled asynchronous motor is connected via an elastomer coupling to the spindle. In addition to the original spindle housing two adjacent outer housings were used to mount the spindle on to the test rig.

The motor, friction in the bearings and the cutting process are the main causes of heat generated by the spindle system during machining operation. The motor is cooled using air flow in the direction from the drive end of the motor to the non-drive end. By assuming that most of the cutting heat is taken out by the coolant and that the heat generated by the motor in the configuration shown in Figure 7 and Figure 8 is kept away from the machine tool spindle, it follows that the heat generated by the bearings is the dominant heat source causing the thermal distortion of the spindle shaft. The motor's maximum continuous duty speed is $7000 \mathrm{rpm}$, with a rated power output of $12 \mathrm{~kW}$. During machining operations such as external cylindrical rough grinding high cutting capacity is required, while during fine grinding a high standard of form and surface quality should be maintained. In order to achieve both mentioned requirements a high degree of rigidity and running accuracy as well as good damping and speed suitability are the main criteria for the spindle bearing arrangement. These requirements are met by the precision bearings assembled in the test spindle. Sealed universal spindle bearings with small steel balls (HSS) are used:

- at the tool end: 1 spindle bearing set, in double $\mathrm{O}$ arrangement (Tandem), as fixed bearings

- at the drive end: 1 spindle bearing set, in $\mathrm{O}$ arrangement, as floating bearings

The employed contact angle of $15^{\circ}$ is suitable for high radial rigidity. The universal design bearings are lightly preloaded. The sealed spindle bearings require no maintenance and are lubricated for life with roller bearing grease [5].

Studying the heat flux mechanisms during spindle operation, the most interesting spindle elements are the spindle bearings, housing and shaft. In order to measure the temperature distribution in axial and radial direction and investigate the heat flux into the machine tool components adjacent to the spindle elements, the spindle system was divided into four cross-sections for temperature measurements. Figure 9 illustrates the measurement sections that were positioned at the bearings axial positions along the spindle system's rotational axis. In radial direction the sensors were positioned along the normal direction of the spindle's outer cylindrical surface, on circles of constant diameter, beginning from the outer ring of the bearing through the original spindle housing and the $1^{\text {st }}$ outer housing up to the $2^{\text {nd }}$ outer housing supporting the spindle as shown in Figure 10. The data acquisition system enables simultaneous measurement, recording and display of the output temperatures from a total of 31 Pt-100 resistance temperature sensors attached in 4-Wire configuration. All 31 sensor positions are shown in 


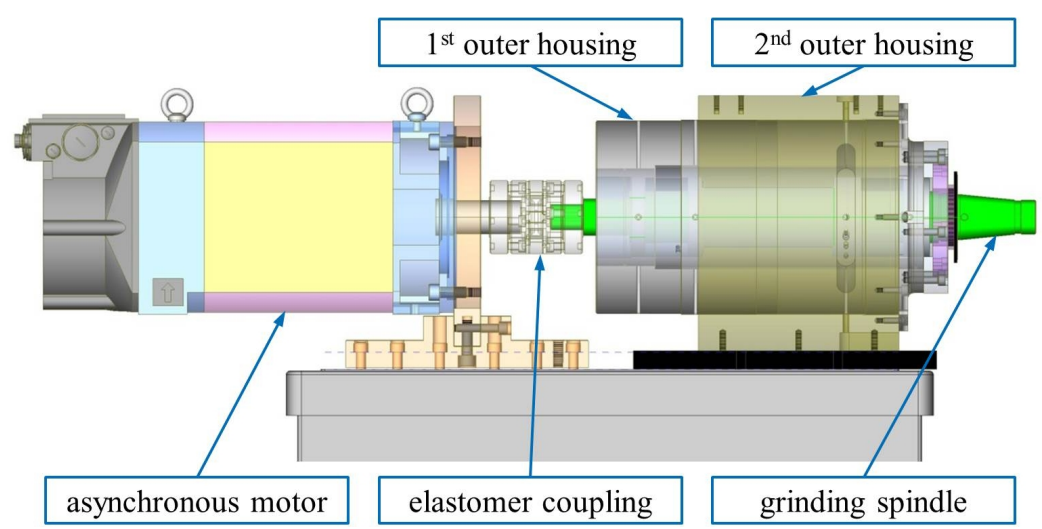

Figure 7. Test rig configuration for the externally driven grinding spindle.

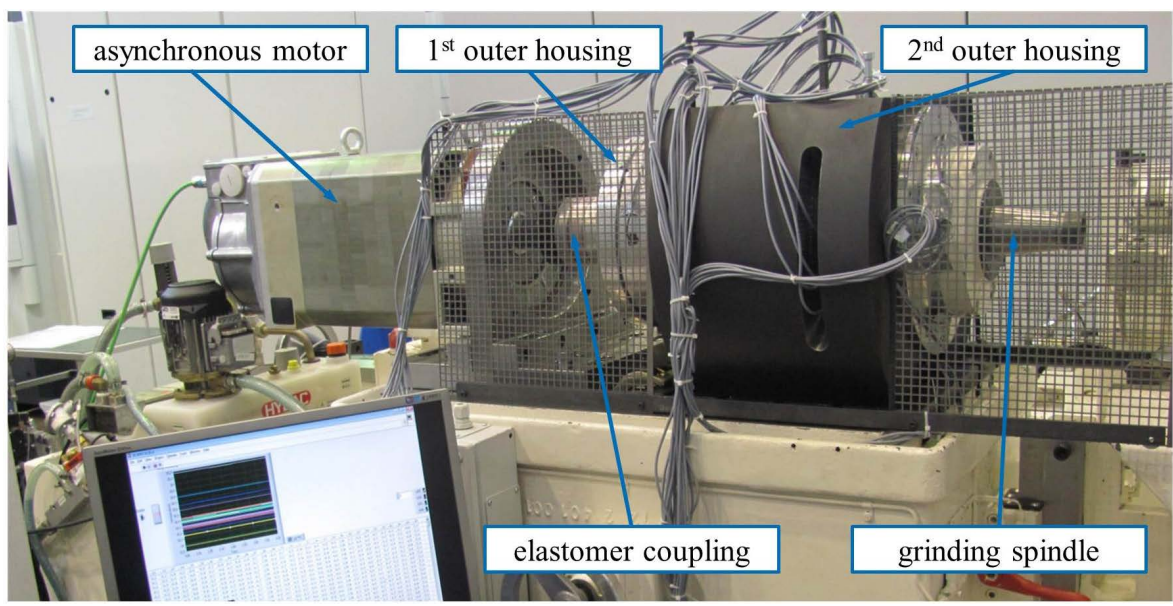

Figure 8. Experimental setup of the sensors and the data acquisition arrangement.

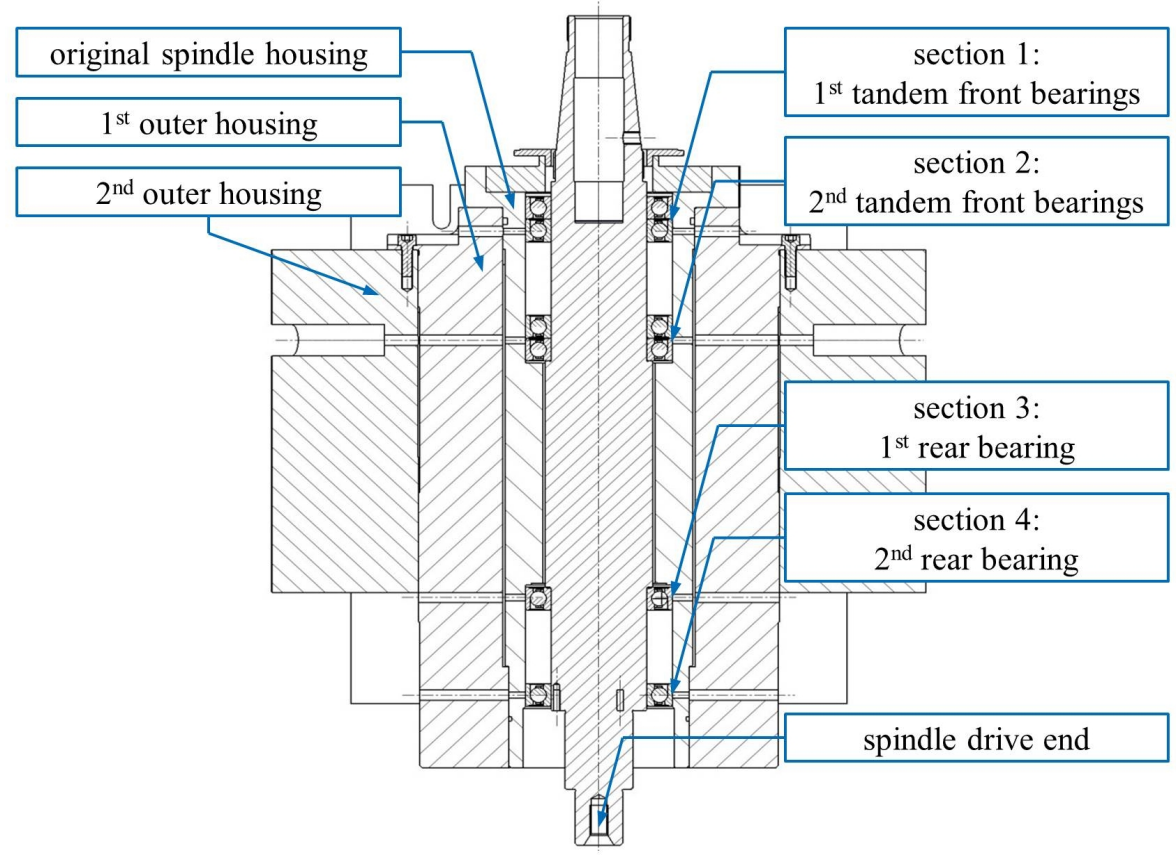

Figure 9. Measuring sections along the spindle axis. 


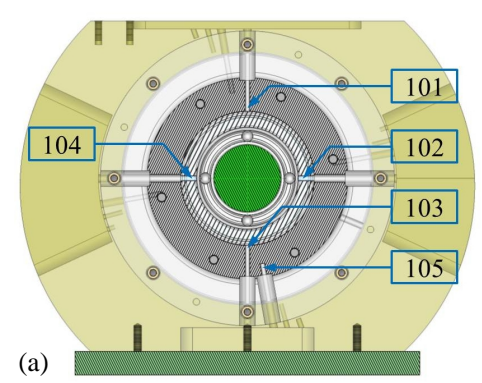

(a)

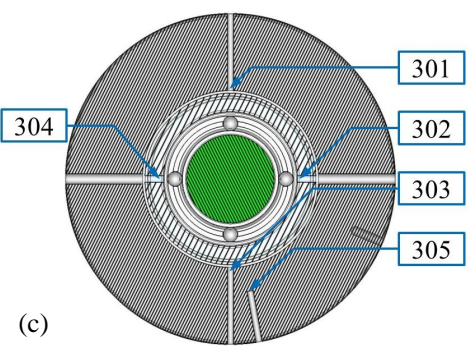

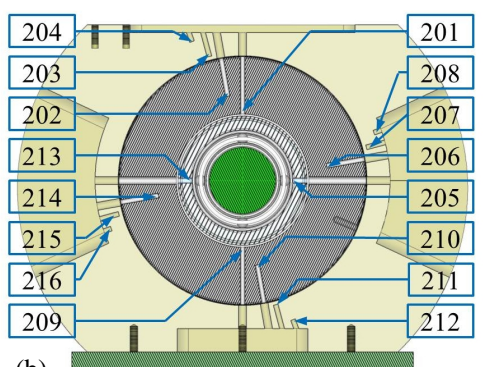

(b)

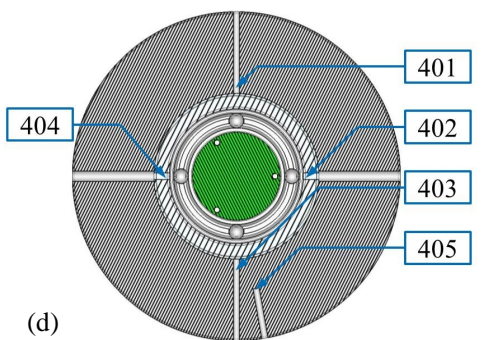

Figure 10. Sensor positions: (a) Section 1; (b) Section 2; (c) Section 3; (d) Section 4.

Figure 10 and the wiring is shown in Figure 8. As mentioned before, the only heat source within the spindle system, during the externally driven spindle operation in the configuration described above is the bearing friction. The heat generation of internal components as a function of spindle speed is only investigated using the test rig described. The research phase is applied in order to gain fundamental knowledge about the heat generation in the spindle system with less complexity. The next step of the investigations will include load-dependent heat generation and heat flux as well as the motorized spindle system's thermal behavior.

\section{Spindle System Thermal Behavior-Experimental Study}

The thermo-elastic behavior of a machine tool is strongly nonlinear and has to be modelled for several operating points. Hence, the speed spectrum has to be divided into several sections, each having its own operating point [2]. Sensitivity analysis under variety of operating modes has been designed and carried out. The spindle speed spectrum up to $7000 \mathrm{rpm}$ is divided into seven operating points starting at $1000 \mathrm{rpm}$ with steps of $1000 \mathrm{rpm}$. The duration of a single step was chosen to be $4 \mathrm{~h}$. The sensor area with the highest temperature in each measurement section was the one located on the bearing outer ring. Figure 11 illustrates the highest measured temperature obtained at spindle speeds from 1000 to 7000 rpm. The sensors mounted in Section 2 present the highest temperature over all spindle speeds. Figure 12 illustrates the steady state temperatures measured in the sections mentioned above according to 3 sensor measurements in each section at $7000 \mathrm{rpm}$ spindle speed. Sensor no. 205 mounted in section 2 at the position directly adjacent to the bearing outer ring. In this position the highest temperature $\left(38.2^{\circ} \mathrm{C}\right.$ ) was achieved. The second highest temperature, $35.4^{\circ} \mathrm{C}$, was measured by sensor no. 302 and $31.8^{\circ} \mathrm{C}$ was measured by sensor no. 102. All 3 sensors mentioned above were mounted in touch with the bearing's outer ring in each section. As shown in Figure 10, 16 sensors are mounted in Section 2. The graph in Figure 13 represents the temperature measured in 5 of the 16 different sensor positions in Section 2. All points across the section from the deepest measuring point, the outer bearing ring, through all 3 housing elements, to the outermost measuring point (sensor no. 204), were heated. Even the outmost point on the outer housing in the $2^{\text {nd }}$ section was affected by the heat generated due to the bearing friction.

By changing the spindle speed over the speed spectrum, from $1000 \mathrm{rpm}$ to $7000 \mathrm{rpm}$, it is clear from Figure 14 that the highest rate of change in the maximum temperature occurs when the rotational speed is increased from 5000 to 7000 rpm. Figure 15 illustrates the influence of spindle speed on the measured temperature in Section 2, sensors no. 201 to 205. As already mentioned, the thermo-elastic behavior of the main spindle system in a machine tool is strongly nonlinear and has to be investigated and modelled in several simplifying steps. First, the thermal behavior of an externally driven spindle was investigated in order to verify and apply a simple simulation model, based only on the heat generated by the friction in the bearings. The heat flux from the bearings into 


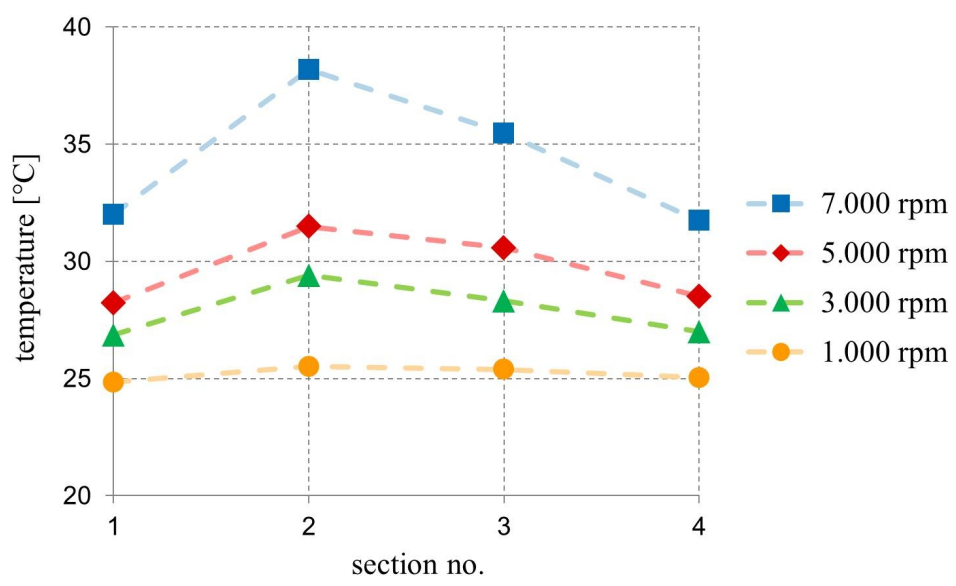

Figure 11. Measured temperature in the most heated sensors among all sections over changing spindle speeds.

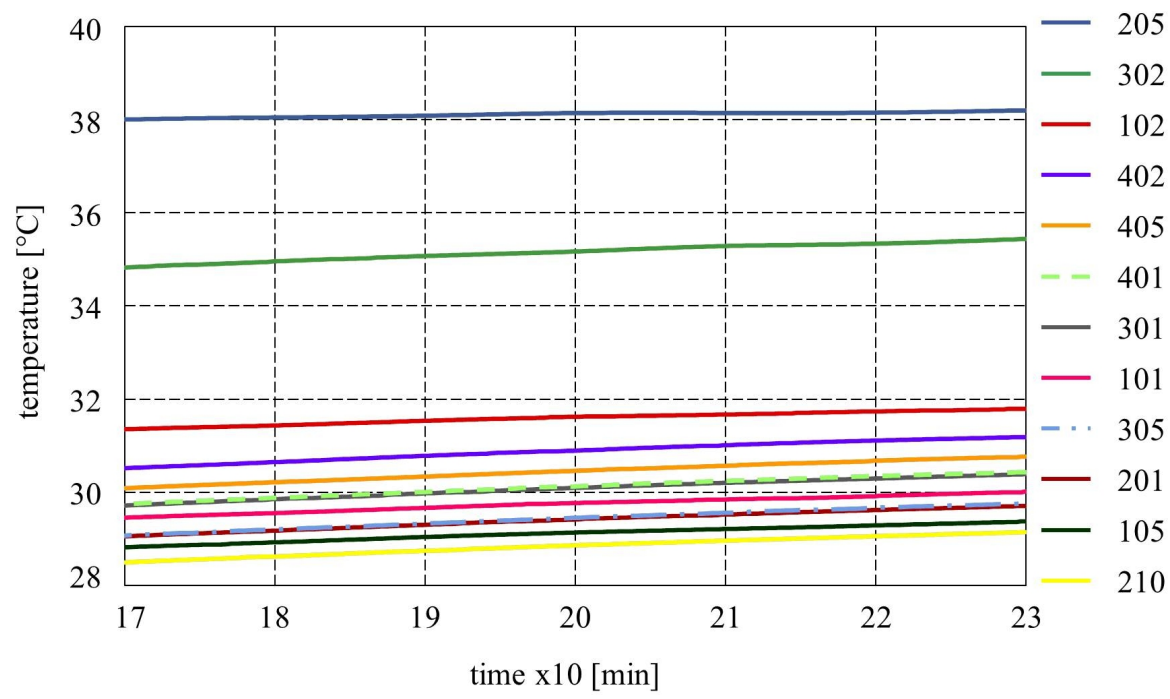

Figure 12. Measured temperature at steady state in 4 Sections; 3 sensors each section.

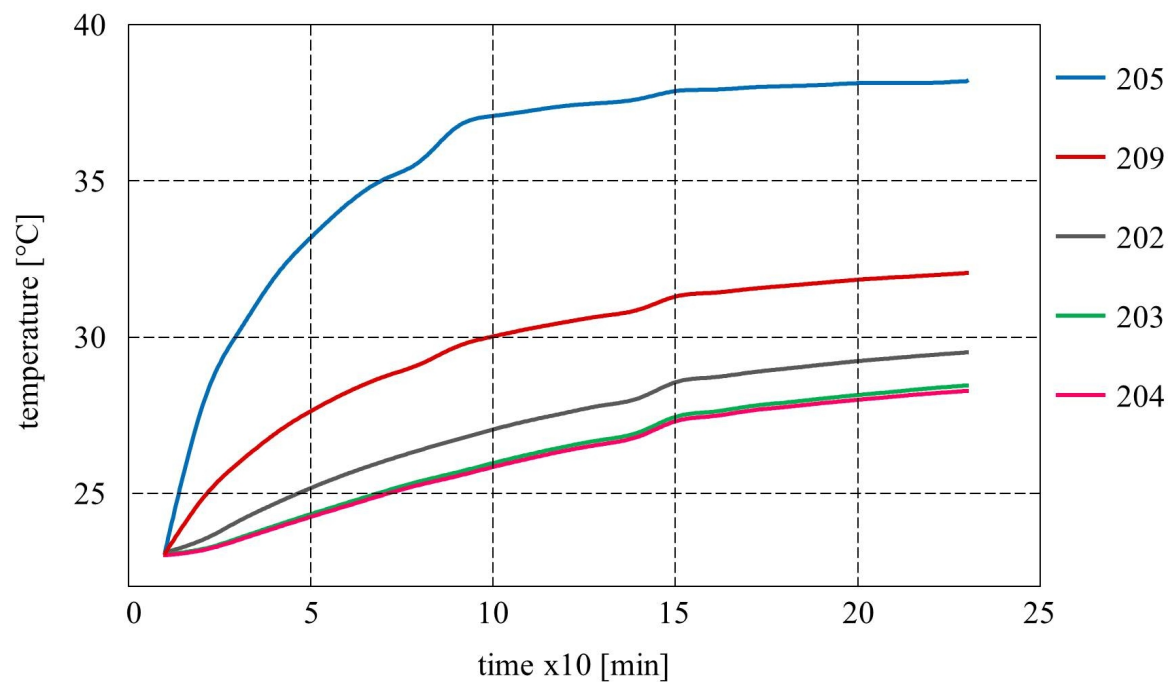

Figure 13. Temperature measured by 5 out of 16 sensors in Section 2. 


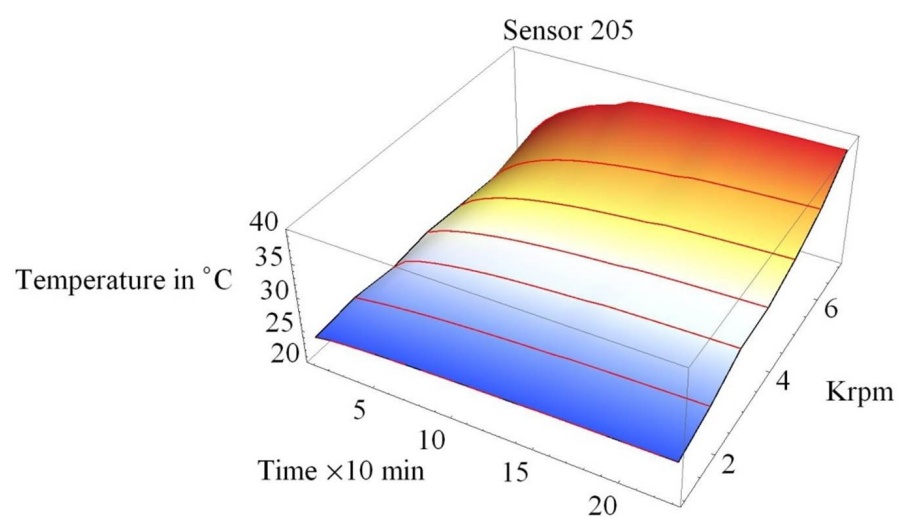

Figure 14. Temperature measured by sensor no. 205, as a function of time and spindle speed.

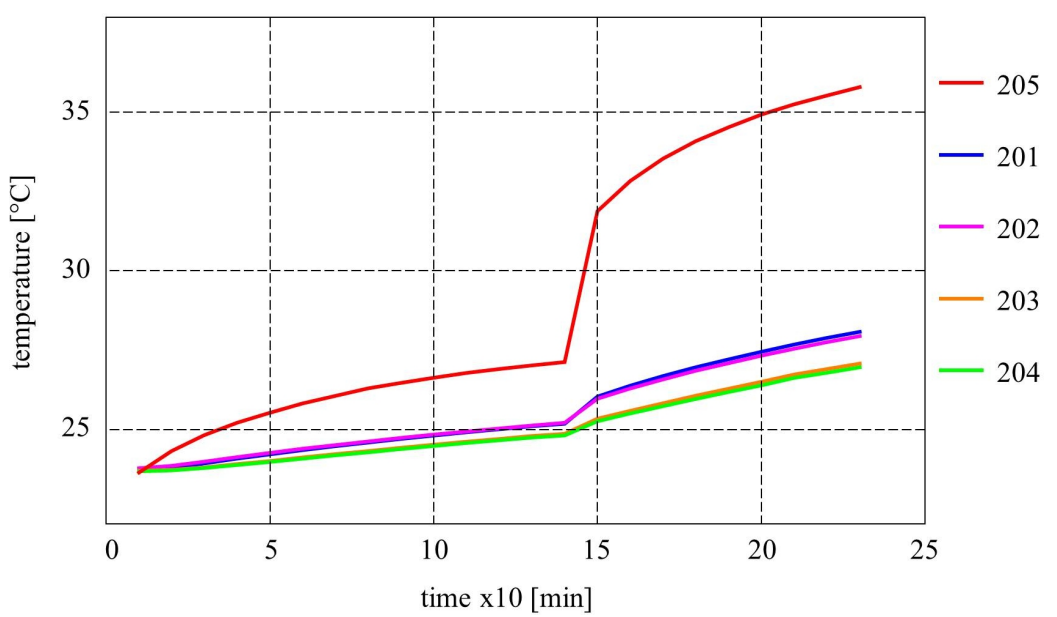

Figure 15. Measured temperature in Section 2 while changing the spindle speed from 3.000 to $7.000 \mathrm{rpm}$.

several outer housings is investigated as well. By verifying the heat transfer from the inner bearings element to the outer housings, one is able to understand the heat flux mechanism and the influence of the heat generated in the bearings on the spindle-adjacent machine elements.

\section{Numerical Simulations}

Based on the model described in Section 2 and Appendices A to D, a simulation program was developed. The numerical computations as well as the graphical presentations and investigations were carried out using the Mathematica ${ }^{\circledR}$ software [16]. Using the algorithm and software developed, numerical studies of the heat transfer mechanism and temperature variations along the external driven spindle system were made. Some simplifications were made in the simulation programs above. No motor and no external cutting load exists in this stage of the study, in order to enable the use of this model as a base line for further simulations including the cutting process effects and motorized spindle simulations.

\subsection{Validation of the Simulation Model}

Due to the fact that a commercial grinding machine spindle was used for the investigations, as described already in Section 3, in this stage of the experimental studies, we focused our experiments on the heat transfer mechanism from the bearings towards the outer housing elements as a function of spindle rotational speed. As stated, the spindle's original geometry, preload, lubrication viscosity, structure or functional elements can not be varied during the investigations. The simulation results are compared with the results obtained in the experimental stu- 
dies described in Section 4. The numerical simulations investigate the effect of operating conditions such as rotational speed (rpm), axial preload, lubricant viscosity, as well as geometrical parameters of the spindle system structural components. Comparison between measured temperatures at the housing outer surface, sensors 101, 201, 301 and 401, and simulated temperature along the axis of the spindle system in the bearings' positions is shown in Figure 16 and Figure 17 for different ranges of spindle rotational speeds.

From Figure 16 and Figure 17 it follows that there is a good fit between the simulation results and the experimental results obtained. It can be seen that the differences are in the range of $1^{\circ} \mathrm{C}$ to $2^{\circ} \mathrm{C}$ over the full range of spindle speeds. It should be mentioned that the main goal of the simulation model is to be fast and efficient and should give first approximation only during an early stage of spindle design. It should not be accurate as a FEM or other simulation software programs, which are much more complex and time consuming.

\subsection{Simulations under Speed Variations}

Internal heat generation and heat flow is strongly speed-dependent. Figure 18 shows the temperature developed in the spindle housing outer surface, $T_{O A}, T_{o B}, T_{O C}, T_{o D}$, at the sections shown in Figure 10. The results can be achieved only by simulation because the spindle and bearings speed limit is $7000 \mathrm{rpm}$.

The temperature profiles in Figure 19 identify the temperatures $T_{l e}$ in the ball bearings' point of contact with the outer and inner rings. These contact points show the highest temperature within the spindle system.

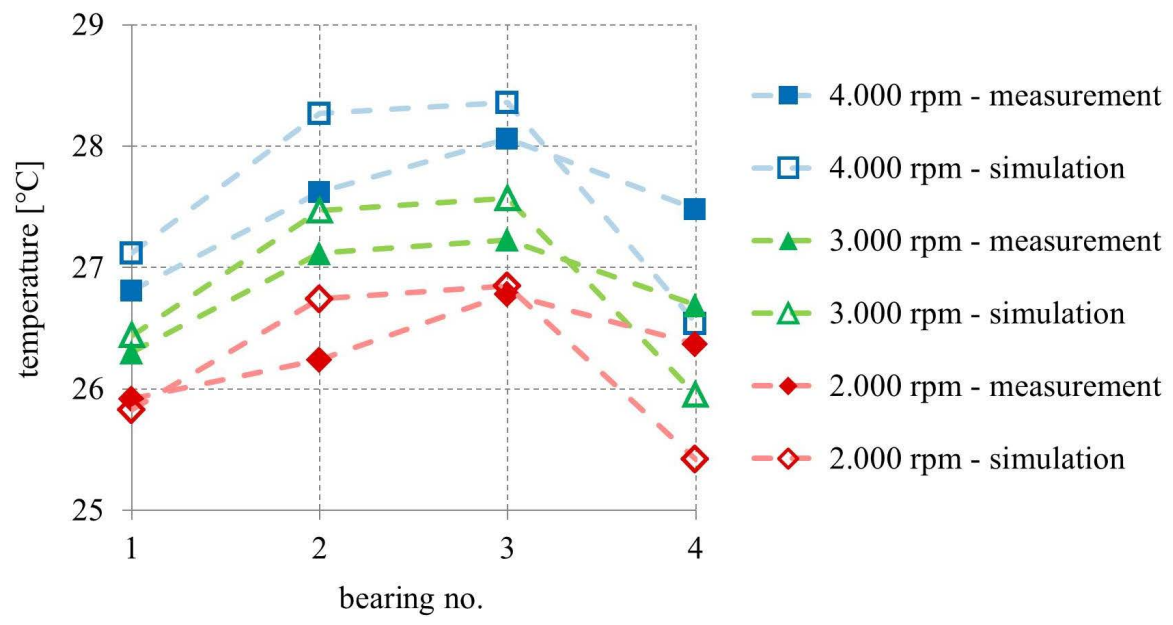

Figure 16. Comparison between measured temperatures and simulated temperature as a function of spindle speeds between 2.000 and $4.000 \mathrm{rpm}$.

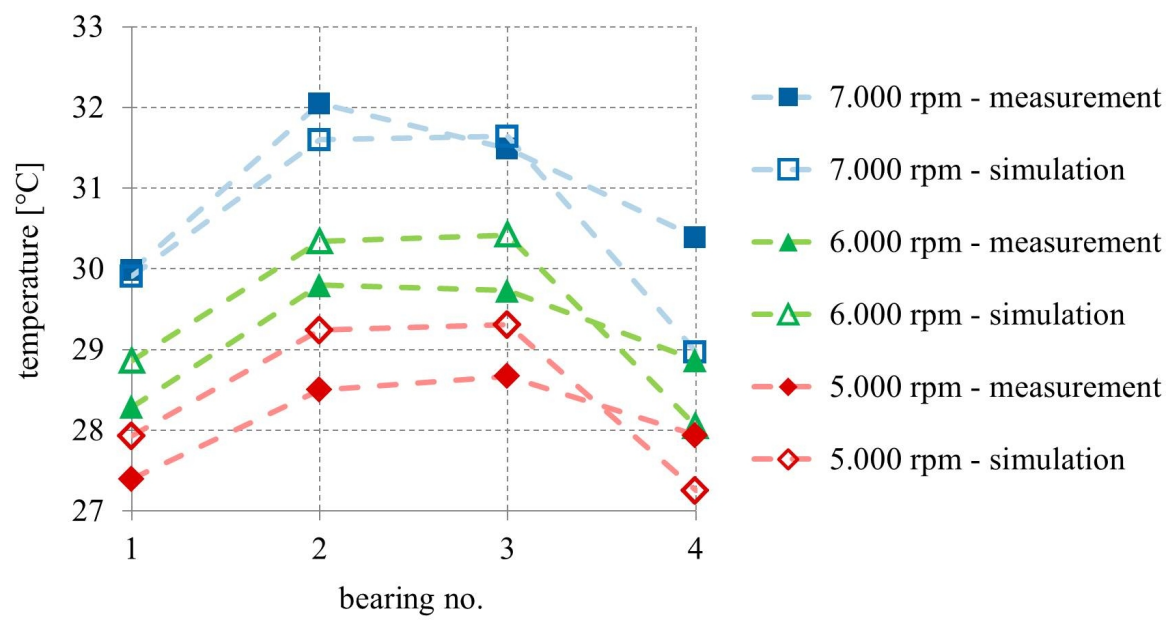

Figure 17. Comparison between measured temperatures and simulated temperature as a function of spindle speeds between 5.000 and $7.000 \mathrm{rpm}$. 
Figure 20 depicts the heat generation $H_{e}$ at the bearing outer ring due to the frictional moments between the bearing balls and the bearing outer ring. According to the developed model and as mentioned in the literature [6], it is assumed that part of the heat generated in the contact flows into the bearing ring and another part flows into the bearing ball. Figure 21 shows the temperature profile along points of interest along the spindle shaft axis, as shown in Figure 6, for various spindle rotational speeds.

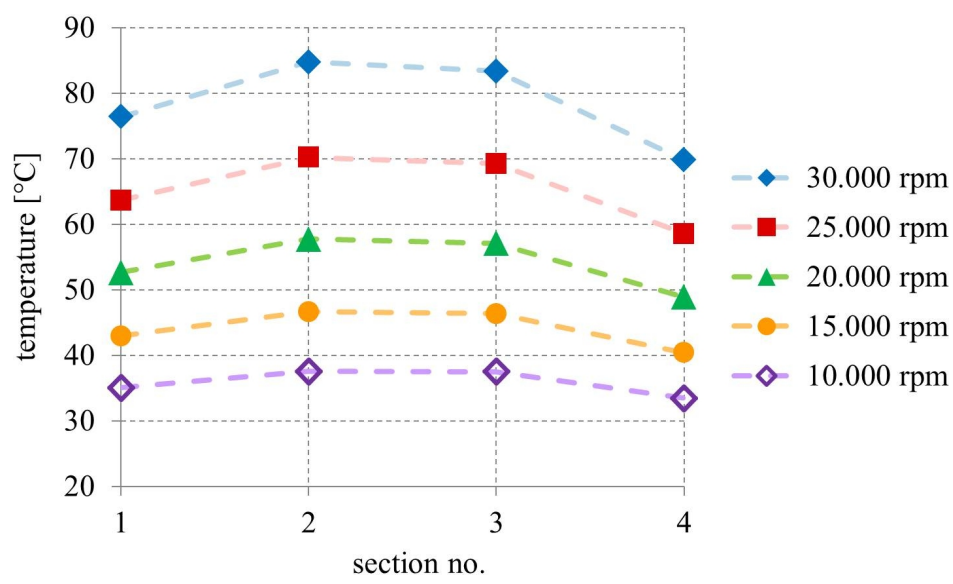

Figure 18. Simulated temperature at changed spindle speed up to 30.000 rpm.

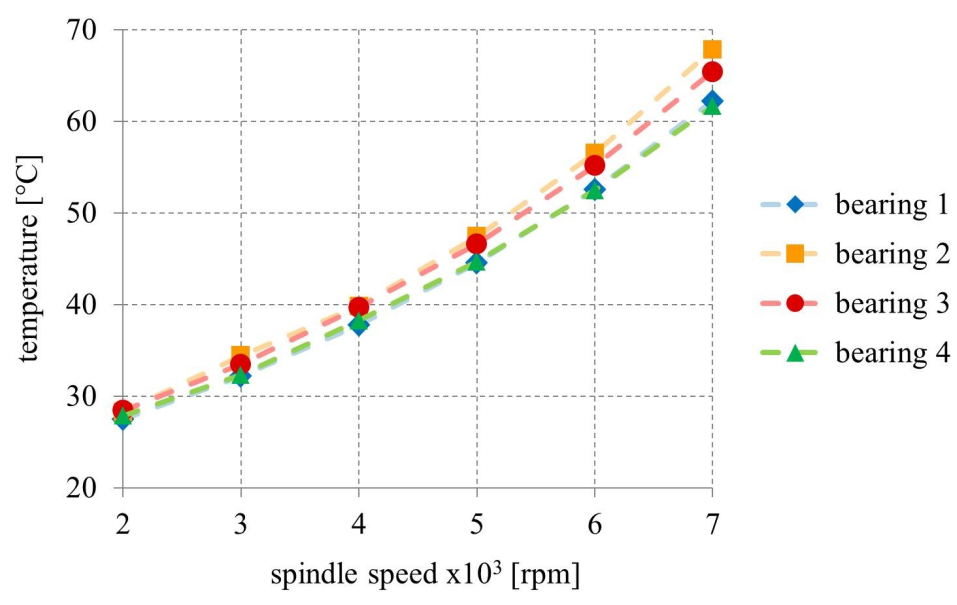

Figure 19. Simulated temperature $T_{l e}$ at the contact point between the bearing ball and the bearing outer ring.

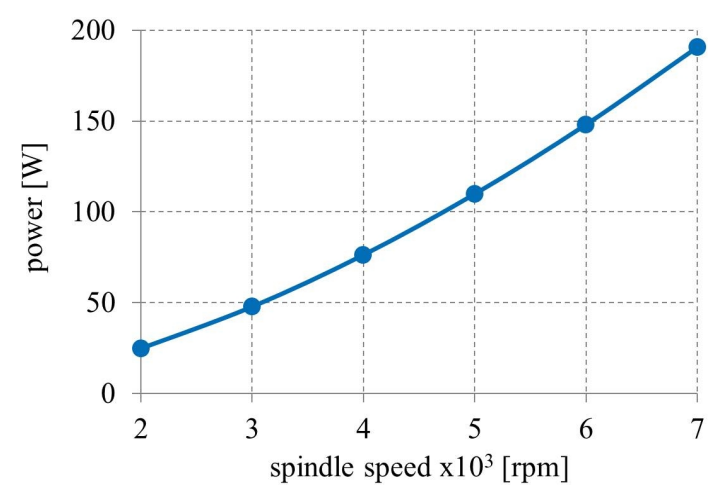

Figure 20. Calculated heat generation at the bearing outer ring as a function of spindle rotational speed. 


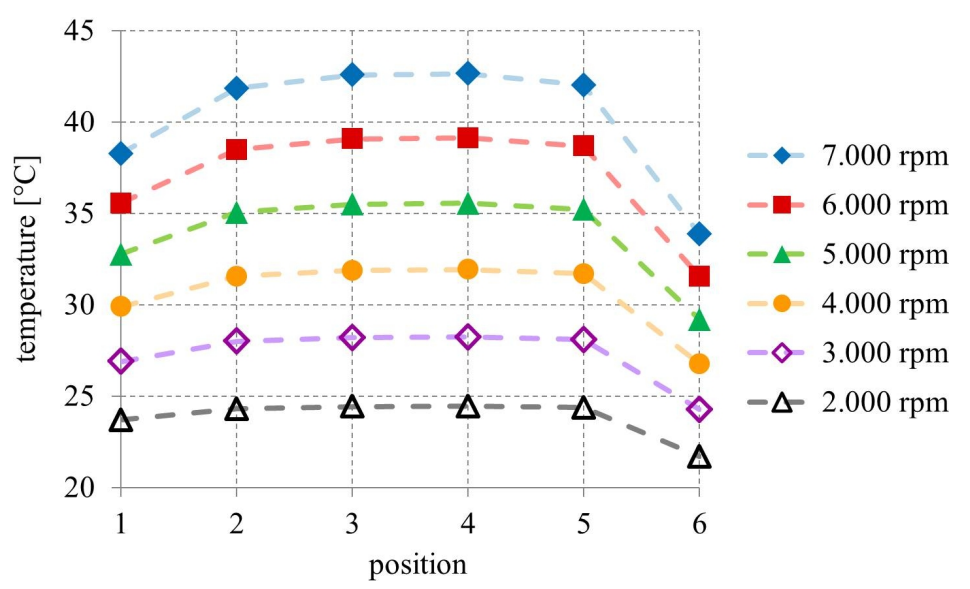

Figure 21. Simulated temperature at 6 points along the spindle shaft axis. $T_{\text {tail }}, T_{i r 1}, T_{i r 2}, T_{i f 1}, T_{i f 2}, T_{\text {tip }}$ over spindle speeds spectrum from 2.000 to $7.000 \mathrm{rpm}$.

\section{Conclusions}

The theoretical and experimental investigations of the heat transfer mechanism in the externally driven grinding spindle have enabled the following conclusions.

1) The use of the bearing heat generation terms in each model, bearing model, spindle model and housing model enabled investigation of the thermal behavior of the entire spindle system under the effect of the main source of heat generation: the bearings' friction.

2) Experimental investigation of the heat transfer in the spindle system and the machine elements adjacent to the spindle allows obtaining the data needed for better understanding the heat generation and flux due to the bearing friction.

3) The simplifying assumptions of the method presented in this study are mainly the one-dimensional heat flow approximations, simplified housing geometry, external drive motor, excluding the cutting process heat and excluding cutting process loads. These spindle-housing approximations are acceptable since the most important temperature predictions are those within the bearings.

4) Using the models presented, the temperature field can be numerically found for most spindle-housing configurations in a fast and efficient manner. The simulated and validated temperature fields can be used for numerical simulations of spindles thermal expansion and machine elements adjacent to the spindle, as well as for machine tool precision prediction during the development process.

\section{Acknowledgements}

The Authors want to thank the DFG (German Research Foundation) for financial support. The represented findings result from the subproject B03 "Investigation of Components and Assembly Groups" of the special research field SFB/Transregio 96 "Thermo-energetic design of machine tools".

\section{References}

[1] Brecher, C. and Wissmann, A. (2011) Compensation of Thermo-Dependent Machine Tool Deformations Due to Spindle Load: Investigation of the Optimal Transfer Function in Consideration of Rough Machining. Production Engineering, 5, 565-574. http://dx.doi.org/10.1007/s11740-011-0311-4

[2] Bryan, J. (1990) International Status of Thermal Error Research. CIRP Annals—Manufacturing Technology, 39, 645656. http://dx.doi.org/10.1016/S0007-8506(07)63001-7

[3] Mayr, J., Jedrzejewski, J., Uhlmann, E., Donmez, M.A., Knapp, W., Härtig, F., et al. (2012) Thermal Issues in Machine Tools. CIRP Annals-Manufacturing Technology, 61, 771-791. http://dx.doi.org/10.1016/j.cirp.2012.05.008

[4] Brecher, C., Fey, M., Neus, S., Shneor, Y. and Bakarinow, K. (2014) Influences on the Thermal Behavior of Linear Guides and Externally Driven Spindle Systems. Production Engineering, 9, 133-141. 
[5] Li, H. and Shin, Y.C. (2004) Analysis of Bearing Configuration Effects on High Speed Spindles Using an Integrated Dynamic Thermo-Mechanical Spindle Model. International Journal of Machine Tools and Manufacture, 44, 347-364. http://dx.doi.org/10.1016/j.ijmachtools.2003.10.011

[6] Jorgensen, B. (1996) Robust Modeling of High-Speed Spindle Bearing Dynamics under Operating Conditions. Ph.D. Thesis, Purdue University, West Lafayette.

[7] Palmgren, A. (1959) Ball and Roller Bearing Engineering. 4th Edition, S.H. Burbank, Philadelphia.

[8] Bossmans, B. and Tu, J. (1999) A Thermal Model for High Speed Motorized Spindles. International Journal of Machine Tools and Manufacture, 39, 1345-1366. http://dx.doi.org/10.1016/S0890-6955(99)00005-X

[9] Li, H. and Shin, Y.C. (2004) Integrated Dynamic Thermo-Mechanical Modeling of High Speed Spindles. Part 1: Model Development. Journal of Manufacturing Science and Engineering, 126, 148-158. http://dx.doi.org/10.1115/1.1644545

[10] Kim, J.D., Zverv, I. and Lee, K.B. (2003) Thermal Model of High-Speed Spindle Units. KSME International Journal, 17, 668-678.

[11] Harris, T.A. (1991) Rolling Bearing Analysis. 3rd Edition, John Wiley \& Sons, Hoboken.

[12] Zhao, H.T., Yang, J.G. and Shen, J.H. (2007) Simulation of Thermal Behavior of a CNC Machine Tool Spindle. International Journal of Machine Tools and Manufacture, 47, 1003-1010.

[13] Harris, T.A. and Kotzalas, M.N. (2005) Advanced Concepts of Bearing Technology, Rolling Bearing Analysis. 5th Edition, Taylor \& Francis Corporations, London.

[14] Cao, Y. (2006) Modeling of High-Speed Machine-Tool Spindle System. Ph.D. Thesis, British Columbia University, British Columbia.

[15] Altintas, Y. and Cao, Y. (2005) Virtual Design and Optimization of Machine Tool Spindles. CIRP Annals-Manufacturing Technology, 54, 379-382.

[16] Wolfram Research (2012) Wolfram Mathematica ${ }^{\circledR}$ 9. Documentation Center. 


\section{Appendix A}

$$
\begin{aligned}
& K=\frac{\pi \kappa E^{\prime}}{3 \boldsymbol{F}} \sqrt{\frac{2 \boldsymbol{E} R_{x y}}{\boldsymbol{F}}} ; \\
& \kappa=1.0339\left(\frac{R_{y}}{R_{x}}\right)^{0.636} ; \\
& \boldsymbol{F}=1.5277+0.6023 \ln \left(\frac{R_{x}}{R_{y}}\right) ; \\
& \boldsymbol{E}=1.0003+0.5968\left(\frac{R_{x}}{R_{y}}\right) ; \\
& E^{\prime}=\frac{2}{\left(\frac{\left(1-\mu_{a}^{2}\right)}{E a}+\frac{\left(1-\mu_{b}^{2}\right)}{E b}\right)} \\
& R_{x y}=\frac{R_{x} R_{y}}{\left(R_{x}+R_{y}\right)} .
\end{aligned}
$$

where $\mu_{a}, \mu_{b}$ are Poisson's ratio of the bearing ball and the rings, respectively. For the inner and outer ring contacts, $R_{x}$ and $R_{y}$ are:

$$
\begin{aligned}
& R_{x i k}=\frac{D\left(1-\gamma_{i k}\right)}{2} ; \quad R_{x o k}=\frac{D \cdot f_{o u}}{2 f_{o u}-1} ; \\
& R_{y i k}=\frac{D \cdot f_{i n}}{2 f_{i n}-1} ; \quad R_{y o k}=\frac{D\left(1+\gamma_{o k}\right)}{2} ; \\
& \gamma_{i k}=\frac{D \cos \theta_{i k}}{D_{m}} ; \quad \gamma_{o k}=\frac{D \cos \theta_{o k}}{D_{m}} .
\end{aligned}
$$

Appendix B

$$
\begin{aligned}
& H_{e}=\frac{T_{L e}-T_{o}}{R_{e}}+\frac{T_{L e}-T_{b}}{R_{1}} ; \quad H_{b}=\frac{T_{b}-T_{L e}}{R_{1}}+\frac{T_{b}-T_{L i}}{R_{2}} ; \quad H_{i}=\frac{T_{L i}-T_{b}}{R_{2}}+\frac{T_{L i}-T_{i}}{R_{i}} \\
& R_{b 11}=\frac{1}{R_{e}}+\frac{1}{R_{1}} ; \quad R_{b 12}=-\frac{1}{R_{1}} ; R_{b 21}=-\frac{1}{R_{1}} ; \quad R_{b 22}=\frac{1}{R_{1}}+\frac{1}{R_{2}} ; \quad R_{b 23}=-\frac{1}{R_{2}} ; \\
& R_{b 32}=-\frac{1}{R_{2}} ; \quad R_{b 33}=\frac{1}{R_{2}}+\frac{1}{R_{i}} .
\end{aligned}
$$

Appendix C

$$
\begin{gathered}
H_{o D}=\frac{T_{o D}-T_{\infty}}{R_{D_{\text {total }}}}+\frac{T_{o D}-T_{o C}}{R_{C_{\text {total }}}} ; \quad H_{o C}=\frac{T_{o C}-T_{o D}}{R_{C_{\text {total }}}}+\frac{T_{o C}-T_{o B}}{R_{B C_{a x}}}+\frac{T_{o C}-T_{h 2}}{R_{B C_{\text {rad }}}} ; \\
H_{o B}=\frac{T_{o B}-T_{o C}}{R_{B C \_a x}}+\frac{T_{o B}-T_{h 2}}{R_{B C \_ \text {rad }}}+\frac{T_{o B}-T_{o A}}{R_{B \_ \text {total }}} ; \quad H_{o A}=\frac{T_{o A}-T_{\infty}}{R_{A_{\_} \text {total }}}+\frac{T_{o A}-T_{o B}}{R_{B \_ \text {total }}} ;
\end{gathered}
$$




$$
\begin{gathered}
R_{h 11}=\frac{1}{R_{A}}+\frac{1}{R_{B}} ; \quad R_{h 12}=-\frac{1}{R_{B}} ; \\
R_{h 21}=-\frac{1}{R_{B}} ; \quad R_{h 22}=\frac{1}{R_{B}}+\frac{1}{R_{B C_{-} a x}}+\frac{1}{R_{B C_{-} r a d}} ; \quad R_{h 23}=-\frac{1}{R_{B C_{-} a x}} ; \\
R_{h 32}=-\frac{1}{R_{B C_{-} a x}} ; \quad R_{h 33}=\frac{1}{R_{C}}+\frac{1}{R_{B C_{-} a x}}+\frac{1}{R_{B C_{-} r a d}} ; \quad R_{h 34}=-\frac{1}{R_{C}} ; \\
R_{h 43}=-\frac{1}{R_{C}} ; \quad R_{h 44}=\frac{1}{R_{C}}+\frac{1}{R_{D}} . \\
R_{A_{-} a x}=\frac{L_{f 1}}{k_{h} \pi\left(r_{A h}^{2}-r_{A o}^{2}\right)}+\frac{1}{h_{a i r} \pi\left(r_{A h}^{2}-r_{A o}^{2}\right)} ; \\
R_{A_{-} \text {rad }}=\frac{\ln \left(\frac{r_{A h}}{r_{A o}}\right)}{k_{h} 2 \pi L_{f 1}}+\frac{1}{h_{a i r} L_{f 1} 2 \pi r_{A h}} ; \\
R_{D_{-} a x}=\frac{L_{r 2}}{k_{h} \pi\left(r_{D h}^{2}-r_{D o}^{2}\right)}+\frac{1}{h_{a i r} \pi\left(r_{D h}^{2}-r_{D o}^{2}\right)} ; \\
R_{D_{-} \text {rad }}=
\end{gathered}
$$

Housing free convection [6]:

$$
\begin{aligned}
& h_{\text {air }}=17.63\left(T-T_{\infty}\right)^{\frac{1}{3}} \text {; } \\
& R_{B_{-} a x}=\frac{L_{f 2}}{k_{h} \pi\left(r_{B h}^{2}-r_{B o}^{2}\right)}+0 ; \\
& R_{\text {B_rad }}=\frac{\ln \left(\frac{r_{B h}}{r_{B o}}\right)}{k_{h} 2 \pi L_{f 2}}+\frac{1}{h_{a i r} L_{f 2} 2 \pi r_{B h}} ; \\
& R_{C_{-} a x}=\frac{L_{r 1}}{k_{h} \pi\left(r_{C h}^{2}-r_{C o}^{2}\right)}+0 \text {; } \\
& R_{C_{-} \text {rad }}=\frac{\ln \left(\frac{r_{C h}}{r_{C o}}\right)}{k_{h} 2 \pi L_{r 1}}+\frac{1}{h_{\text {air }} L_{r 1} 2 \pi r_{C h}} ; \\
& R_{B C \_ \text {rad }}=\frac{\ln \left(\frac{r_{B C h}}{r_{B C o}}\right)}{k_{h} 2 \pi L}+\frac{1}{h_{\text {air }} L 2 \pi r_{B C h}} ; \\
& R_{B C \_a x}=\frac{L}{k_{h} \pi\left(r_{B C h}^{2}-r_{B C o}^{2}\right)}+0 . \\
& R_{A_{\_} \text {total }}=\frac{R_{A_{\_} a x} \times R_{A_{\_} \text {rad }}}{R_{\mathrm{A}_{\_} a x}+R_{\mathrm{A}_{\_} \text {rad }}} ; R_{B_{\_} \text {total }}=\frac{R_{B_{B} a x} \times R_{B_{\_} \text {rad }}}{R_{B_{\_} a x}+R_{B_{\_} \text {rad }}} ; \\
& R_{C_{-} \text {total }}=\frac{R_{C_{\_} a x} \times R_{C_{\_} \text {rad }}}{R_{C_{\_} a x}+R_{C_{-} \text {rad }}} ; R_{D_{-} \text {total }}=\frac{R_{D_{-} a x} \times R_{D_{\_} \text {rad }}}{R_{D_{-} a x}+R_{D_{-} \text {rad }}} \text {. }
\end{aligned}
$$




\section{Appendix D}

$$
\begin{aligned}
& 0=\frac{T_{\text {tail }}-T_{r \infty}}{R_{\text {tail }}}+\frac{T_{\text {tail }}-T_{i r 1}}{R_{M}} ; \quad H_{i D}=\frac{T_{i r 1}-T_{\text {tail }}}{R_{M}}+\frac{T_{i r 1}-T_{i r 2}}{R_{N}} ; \quad H_{i C}=\frac{T_{i r 2}-T_{i r 1}}{R_{N}}+\frac{T_{i r 2}-T_{i f 1}}{R_{O}} ; \\
& H_{i B}=\frac{T_{i f 1}-T_{i r 2}}{R_{O}}+\frac{T_{i f 1}-T_{i f 2}}{R_{P}} ; \quad H_{i A}=\frac{T_{i f 2}-T_{i f 1}}{R_{P}}+\frac{T_{i f 2}-T_{t i p}}{R_{Q}} ; \quad 0=\frac{T_{t i p}-T_{i f 2}}{R_{Q}}+\frac{T_{\text {tip }}-T_{f \infty}}{R_{\text {tip }}} \text {. } \\
& R_{M}=\sum_{j=1}^{i r 1-1} R_{j}+\frac{1}{2} R_{i r 1}=R_{1}+R_{2}+\frac{1}{2} R_{i r 1} \text {; } \\
& R_{N}=\sum_{j=i r 1+1}^{i r 2-1} R_{j}+\frac{1}{2} R_{i r 1}+\frac{1}{2} R_{i r 2}=R_{3}+\frac{1}{2} R_{i r 1}+\frac{1}{2} R_{i r 2} ; \\
& R_{O}=\sum_{j=i r 2+1}^{i f 1-1} R_{j}+\frac{1}{2} R_{i r 2}+\frac{1}{2} R_{i f 1}=R_{4}+\frac{1}{2} R_{i r 2}+\frac{1}{2} R_{i f 1} \text {; } \\
& R_{p}=\sum_{j=i f 1+1}^{i f 2-1} R_{j}+\frac{1}{2} R_{i f 1}+\frac{1}{2} R_{i f 2}=R_{5}+\frac{1}{2} R_{i f 1}+\frac{1}{2} R_{i f 2} \text {; } \\
& R_{Q}=\sum_{j=i f 2+1}^{n} R_{j}+\frac{1}{2} R_{i f 2}=R_{6}+R_{7}+\frac{1}{2} R_{i f 2} \text {. } \\
& R_{i 11}=\frac{1}{R_{\text {tail }}}+\frac{1}{R_{M}} ; \quad R_{i 12}=-\frac{1}{R_{M}} ; \\
& R_{i 21}=-\frac{1}{R_{M}} ; \quad R_{i 22}=\frac{1}{R_{M}}+\frac{1}{R_{N}} ; \quad R_{i 23}=-\frac{1}{R_{N}} ; \\
& R_{i 32}=-\frac{1}{R_{N}} ; \quad R_{i 33}=\frac{1}{R_{N}}+\frac{1}{R_{O}} ; \quad R_{i 34}=-\frac{1}{R_{O}} ; \\
& R_{i 43}=-\frac{1}{R_{O}} ; \quad R_{i 44}=\frac{1}{R_{O}}+\frac{1}{R_{P}} ; \quad R_{i 45}=-\frac{1}{R_{P}} ; \\
& R_{i 54}=-\frac{1}{R_{P}} ; \quad R_{i 55}=\frac{1}{R_{P}}+\frac{1}{R_{Q}} ; \quad R_{i 56}=-\frac{1}{R_{Q}} ; \\
& R_{i 65}=-\frac{1}{R_{Q}} ; \quad R_{i 66}=\frac{1}{R_{Q}}+\frac{1}{R_{t i p}} .
\end{aligned}
$$


Scientific Research Publishing (SCIRP) is one of the largest Open Access journal publishers. It is currently publishing more than 200 open access, online, peer-reviewed journals covering a wide range of academic disciplines. SCIRP serves the worldwide academic communities and contributes to the progress and application of science with its publication.

Other selected journals from SCIRP are listed as below. Submit your manuscript to us via either submit@scirp.org or Online Submission Portal.
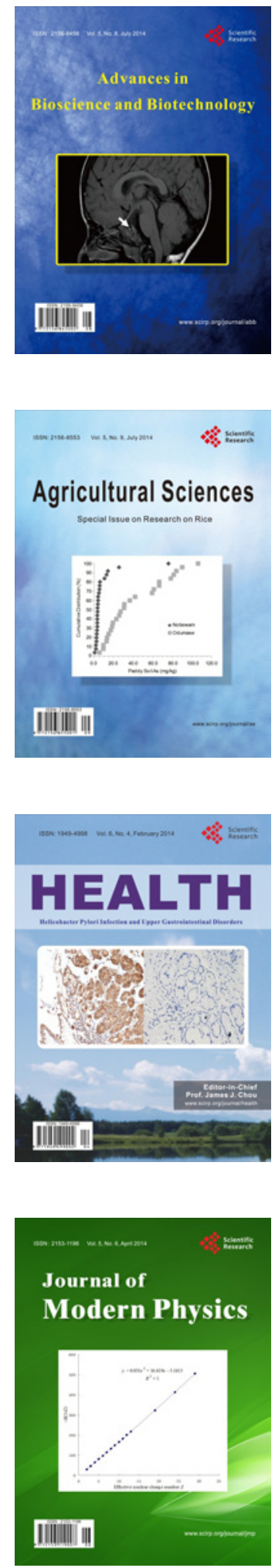
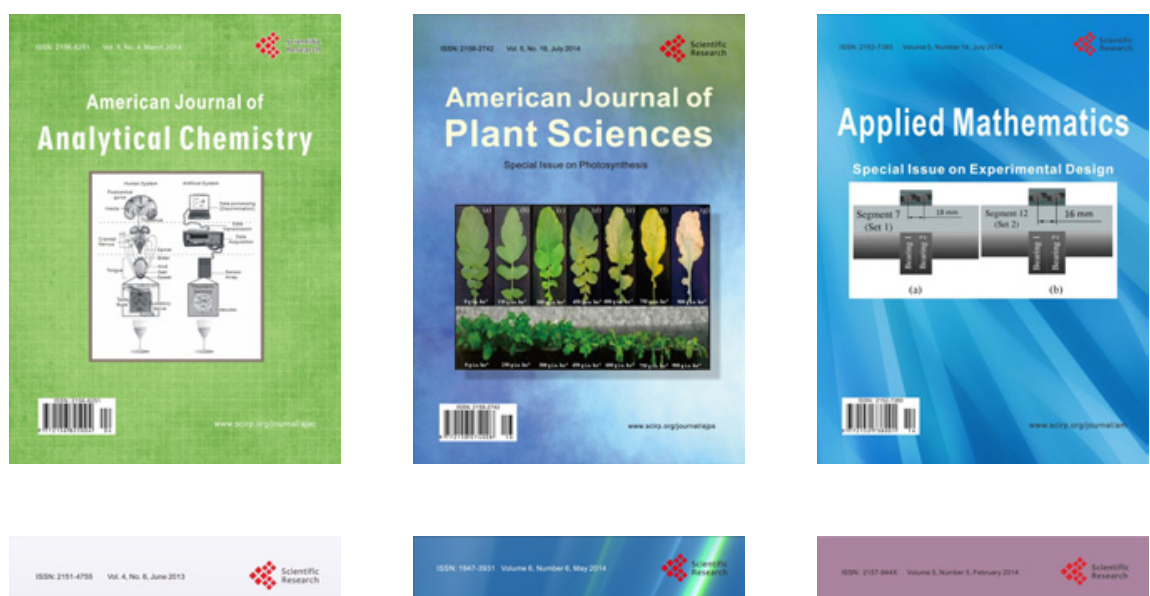

Creative Education
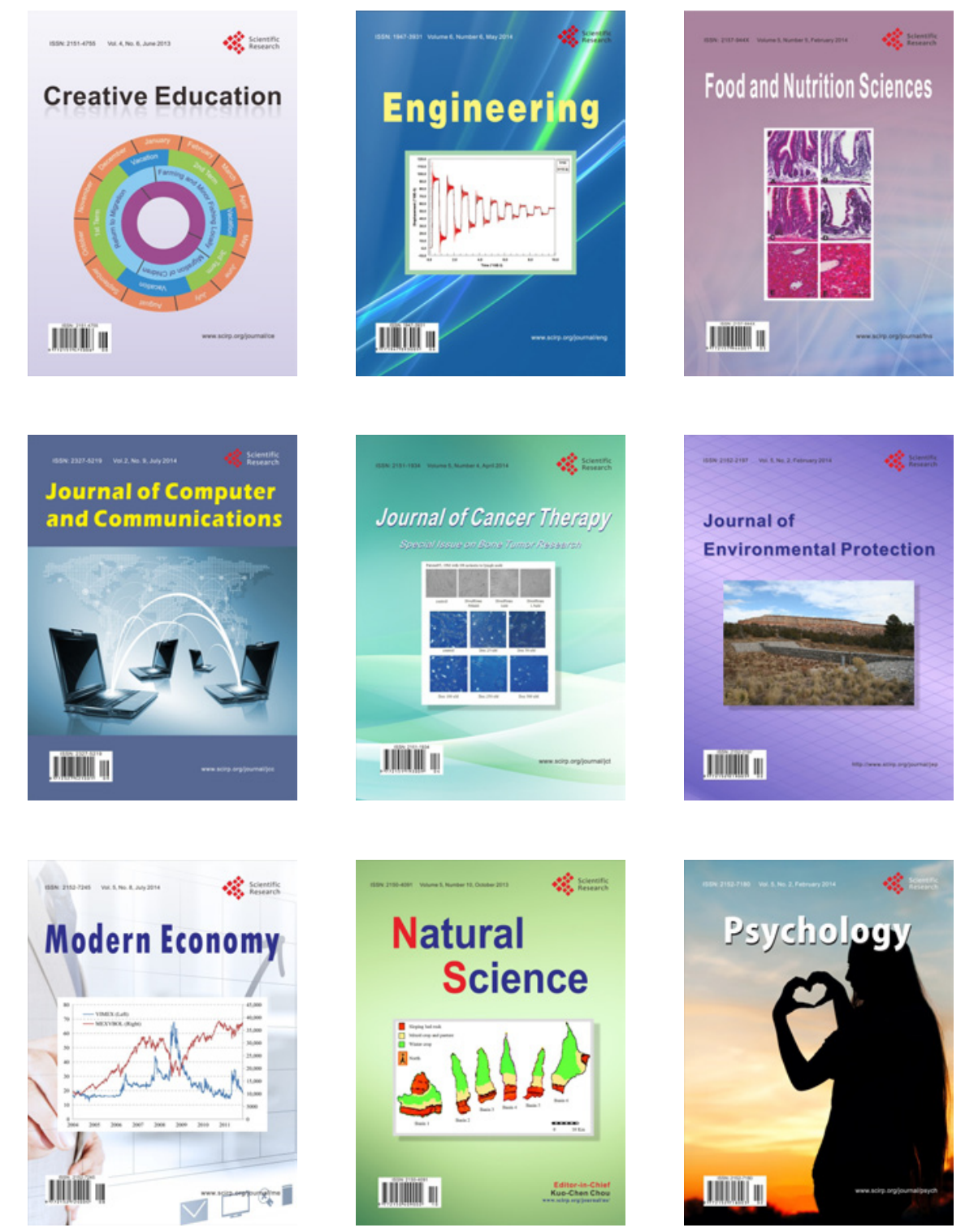